\title{
Tranexamic acid administration time to prevent bleeding in total knee arthroplasty: preliminary data
}

\author{
C. Teixell, C. Moreno, A. Pardo, C. Luis, X. Santiveri, E. Bisbe \\ Hospital Parc de Salut Mar, Barcelona
}

\section{Background}

Tranexamic acid has clearly demonstrated its effectiveness in reducing blood loss and transfusion requirements in major orthopedic surgery. However, the ideal timing of its administration is not well established in total knee prosthesis surgery with tourniquet.

\section{Objective}

The aim of this study is to know if the moment of the tranexamic acid administration (at induction or before relieving the tourniquet) influences the perioperative bleeding on knee arthroplasty.

\section{Material and methods}

Prospective, double-blind clinical trial (EudraCT 2016-000071-24) of the first 99 primary knee arhroplasty patients operated with tourniquet. Patients were randomized in 2 groups: in the Induction group tranexamic acid was administered before starting the ischemia while in the Ischemia group it was administered 20-30 minutes before relieving the tourniquet.

The 2 groups were compared using Student's T for qualitative variables and a Shi square for quantitative variables. We considered statistically significant a $p<0.05$.

\section{Results and discussion}

The two groups were comparable in sex, age, ASA, preoperative haemoglobin $(\mathrm{Hb})$ and duration of surgery. In the Induction group the visible bleeding in the drain was significantly lower than in the Ischemia group. We found no significant differences between $\mathrm{Hb}$ at $24 \mathrm{~h}$ and at discharge, neither in calculated total bleeding; but it could be due to a lack of statistical power because of the number of patients included wasn't big enough. There were few complications, with no differences between groups.

\begin{tabular}{|c|c|c|c|}
\hline Groups & Induction & Ischemia & p \\
\hline Visible bleeding in drain $(\mathbf{m l})$ & $142 \mathrm{ml}$ & $213 \mathrm{ml}$ & 0.005 \\
\hline Calculated total bleeding $(\mathbf{m l})$ & $1568 \mathrm{ml}$ & $1595 \mathrm{ml}$ & 0.82 \\
\hline Hb at 24h (g/dl) & 11.9 & 11.7 & 0.65 \\
\hline Hb at discharge (g/dl) & 10.62 & 10.6 & 0.93 \\
\hline Hospital Stay (days) & 5.4 & 4,6 & 0.27 \\
\hline
\end{tabular}

\section{Conclusions}

In these preliminary results, it seems that the administration of tranexamic acid before the induction significantly reduced visible bleeding in the drain without impact on complications. 